\title{
Effect of Hydrogen Peroxide Exposure on Normal Human Erythrocyte Deformability, Morphology, Surface Characteristics, and Spectrin-Hemoglobin Cross-linking
}

\author{
L. M. Snyder, N. L. Fortier, J. Trainor, J. Jacobs, and L. Leb \\ Department of Hematology and Pathology, St. Vincent Hospital, Worcester, Massachusetts 01604 \\ B. Lubin and D. Chiu \\ Childrens' Hospital Medical Center, Oakland, California 94609
}

S. Shohet and N. Mohandas

Division of Cancer Research, School of Medicine, University of California at San Francisco, California 94143

\begin{abstract}
To further define the conditions for forming spectrin-hemoglobin cross-linking in human erythrocyte membranes and to examine its possible effects on membrane function, we incubated normal human erythrocytes for up to $3 \mathrm{~h}$ in concentrations of $\mathrm{H}_{2} \mathrm{O}_{2}$, varying from 45 to $180 \mu \mathrm{M}$, in an azide phosphate buffer, $\mathrm{pH}$ 7.4. The chemical changes observed indicated that methemoglobin formation occurred early and at a low concentration $(45 \mu \mathrm{M})$. Morphologic changes characterized by increased echinocyte formation occurred in a dose-dependent fashion. In addition, decreased cell deformability commensurate with increased membrane rigidity was found. Finally, an increase in cell recognition as determined by monocyte phagocytosis and adherence in vitro, as well as decreased phosphatidylcholine accessibility to bee venom phospholipase $A_{2}$, was found in $\mathrm{H}_{2} \mathrm{O}_{2}$-treated erythrocytes compared with controls. Both of these latter changes were closely correlated with the extent of spectrin-hemoglobin cross-linking.

In addition to these protein-mediated interactions, lipid peroxidation also occurred after $\mathrm{H}_{2} \mathrm{O}_{2}$ exposure, as shown by generation of fluorescent amino propene derivatives. The addition of the antioxidant, butylated hydroxytoluene, decreased the fluorescent derivatives, but did not prevent the effects on membrane function. This suggests that lipid peroxidation, though present, was not necessary for the membrane changes found. In contrast, spectrin-hemoglobin aggregation and the alterations in membrane function were completely prevented by prior exposure of the erythrocytes to carbon monoxide.
\end{abstract}

\section{Introduction}

On the basis of cell density, circulating normal erythrocytes can be separated into distinct populations with defined cell water content using various density gradient separation procedures (1, 2). Biochemical, biophysical, and immunological characterizations of these separated cell populations have been carried out by a number of investigators in order to define the cellular basis

Address correspondence to Dr. Snyder, Director, Division of Hematology, St. Vincent Hospital, 25 Winthrop St., Worcester, MA 01604.

Received for publication 29 January 1985 and in revised form 24 May 1985.

J. Clin. Invest.

(C) The American Society for Clinical Investigation, Inc.

0021-9738/85/11/1971/07 \$1.00

Volume 76, November 1985, 1971-1977 for erythrocyte senescence (3). In spite of a wealth of information generated during the last decade, there is yet no consensus concerning the cardinal cellular change that may signal the removal of the senescent cell from circulation. This may in part be due to the fact that the erythrocyte aging process is a multifactorial event, and understanding of the interrelationship between various cellular changes is essential to define the complex process of senescent cell recognition.

We recently reported that an irreducible complex between the globin chain of hemoglobin and spectrin is formed by an oxidative mechanism during the erythrocyte aging process and we correlated this complex with other evidence of oxidative damage to the erythrocyte $(4,5)$. A direct role for this spectringlobin complex in erythrocyte senescence was questioned because of its magnitude ( $<4 \%$ of the total spectrin) and because its effect on various cellular and membrane properties was not well understood (6).

Spectrin, a major protein component of the erythrocyte membrane skeletal system, performs a variety of membrane functions, including the regulation of membrane deformability and stability (7). In addition, spectrin may also regulate cell shape and surface characteristics by its ability to attach to the lipid bilayer and to the integral membrane protein, band $3(8)$. Since spectrin appears to play a pivotal role in regulating important cellular properties, we investigated the effects of spectrin-globin complex on erythrocyte deformability, shape, and surface characteristics.

The spectrin-globin complex found in dense, dehydrated erythrocytes isolated from whole blood could be reproduced in vitro by treating erythrocytes with low concentrations of $\mathrm{H}_{2} \mathrm{O}_{2}$, and could be completely inhibited by pretreatment of cells with carbon monoxide, which interferes with heme protein peroxidative reactions. We used this system to study the effects of spectrin-globin complex on various erythrocyte properties. Progressive accumulation of spectrin-globin complex was associated with progressive echinocyte formation, increased membrane rigidity, and increased adherence and phagocytosis of altered erythrocytes by monocytes. Pretreatment with carbon monoxide inhibited the formation of the protein complex as well as the resultant cellular changes.

\section{Methods}

Control and hydrogen peroxide-treated cells were shipped at $4^{\circ} \mathrm{C}$ in the original citrate phosphate dextrose plasma to San Francisco and Oakland, CA for deformability and lipid analysis. All the samples were analyzed within $24 \mathrm{~h}$ after experimental manipulations. In order to be certain that cellular changes during transportation did not affect the measurements, 
all the measurements were performed on freshly treated erythrocytes on at least one occasion in the Bay area.

Normal human erythrocyte suspensions. Erythrocyte suspensions were prepared from heparinized fresh human blood obtained from laboratory volunteers. After centrifugation, to remove the plasma and leukocytes the erythrocytes were washed three times in a phosphate-buffered saline (PBS; $10 \mathrm{mM}$ ), $\mathrm{pH} 7.4$, enriched with $5.0 \mathrm{mM}$ glucose. In certain experiments washed erythrocytes were exposed for $10 \mathrm{~min}$ to carbon monoxide in order to stabilize hemoglobin in the oxy configuration and block its function as an electron trap, and therefore, to prevent formation of methemoglobin upon exposure to hydrogen peroxide. The washed erythrocytes were adjusted to a hematocrit of $20 \%$ in glucose-enriched phosphate-buffered saline with $1.0 \mathrm{mM}$ sodium azide. Hydrogen peroxide was added to the cell suspension to give a final concentration in the range of 45 to $810 \mu \mathrm{M}$. The cell suspension was incubated at $37^{\circ} \mathrm{C}$ in a shaking water bath for varying periods of time. In some experiments, washed cells were preincubated for $\mathbf{3 0} \mathrm{min}$ with the antioxidant, butylated hydroxytoluene (BHT), ${ }^{1}$ at a concentration of $0.2 \mathrm{mM}$ before addition of $\mathrm{H}_{2} \mathrm{O}_{2}$.

Chemical determinations. Methemoglobin, intracellular sodium, potassium, and erythrocyte indices were determined by standard procedures (9). Extent of lipid peroxidation was quantitated by measuring the fluorescent amino immunopropene derivatives as described by Goldstein et al., (10) using a scaled down version of the Rose and Oklander (11) chloroform isopropanol extraction procedure using $0.05 \mathrm{ml}$ of washed packed erythrocytes.

The fluorescent derivatives were measured in an Amico-Bowman spectrofluorometer (American Instrument Co. Inc., Silver Springs, MD) at $25^{\circ} \mathrm{C}$ with an excitation maximum of $360 \mathrm{~nm}$ and an emission maximum of $440 \mathrm{~nm}$. Fluorescence was recorded in arbitrary units at these settings. The reading of $10^{-8} \mathrm{M}$ quinine sulphate in $\mathrm{H}_{2} \mathrm{SO}_{4}$ was $50 \mathrm{flu}$ orescent units at standard instrument settings.

Electrophoretic analysis of membrane proteins. The membrane ghosts were prepared by hypotonic hemolysis as described previously (9). Equal amounts of the sodium dodecyl sulfate (SDS)-solubilized membrane proteins obtained from a defined number of ghosts were run on cylindrical $4 \%$ polyacrylamide gels as described previously (9).

The percentage of spectrin-hemoglobin complex was carefully calculated by integrating the Coomassie Blue stain profile on the densitometric scans. The area of the spectrin region (bands 1 and 2) from control nontreated cells was carefully superimposed on the scans of the spectrin region from $\mathrm{H}_{2} \mathrm{O}_{2}$-treated cells. The difference in the area noted at the trailing edge of band 1 in the treated cells which represents spectrinhemoglobin cross-linking (4) was carefully cut out, weighed, and then expressed as a percent of the total spectrin.

Membrane phospholipid organization of hydrogen peroxide-treated erythrocytes. Treatment of erythrocytes with phospholipase $A_{2}$ and sphingomyelinase $\mathrm{C}$ was carried out according to previously described methods (12). A $0.10-\mathrm{ml}$ aliquot of packed erythrocytes was resuspended in $5.0 \mathrm{ml}$ of $50 \mathrm{mM}$ phosphate buffer containing $5.0 \mathrm{mM} \mathrm{KCl}, 120 \mathrm{mM}$ $\mathrm{NaCl}, 0.25 \mathrm{mM} \mathrm{Mg}^{+2}$, and $0.5 \mathrm{mM} \mathrm{Ca}{ }^{+2}, \mathrm{pH}$ 7.4. $50 \mathrm{IU}$ of phospholipase $\mathrm{A}_{\mathbf{2}}$ from bee venom (Sigma Chemical Co., St. Louis, MO) and/or 6 IU of sphingomyelinase from Staphylococcus aureus purified by the method of Zwaal et al. (13) was then added to the cell suspension and incubated at $37^{\circ} \mathrm{C}$ for varying periods of time. The purity of both phospholipase $\mathrm{A}_{2}$ from bee venom and sphingomyelinase from $S$. aureus was assessed by SDS-polyacrylamide gel electrophoresis. A single band was detected with both enzyme preparations.

The degradation of phospholipid by phospholipase $\mathrm{A}_{2}$ or sphingomyelinase was terminated by washing the erythrocyte three times with PBS containing 5.0 mM EDTA. The extent of hemolysis was determined at the end of each incubation before the EDTA wash by comparing the hemoglobin content in the supernate of each sample with that of a $100 \%$ hemolyzed control.

1. Abbreviations used in this paper: BHT, butylated hydroxytoluene; DI, deformability index; PC, phosphatidylcholine; SM, sphingomyelin.
Determination of phospholipid degradation by phospholipase $A_{2}$ and sphingomyelinase $C$. Phospholipase-treated and control erythrocyte samples were washed with PBS and were subjected to lipid extraction by the method of Rose and Oklander (11). Lipid extracts from each sample were evaporated to dryness under nitrogen and redissolved in a small volume (100-200 $\mu \mathrm{l}$ ) of 2:1 chloroform/methanol mixture. Individual phospholipids were separated by the two-dimensional, thin-layer chromatographic technique described by Roelofsen and Zwaal (14). The individual lipid components were examined by staining with iodine vapor. All spots were scraped from the plate and transferred to test tubes, and the quantity of phospholipid was determined by measuring the amount of phosphorous in each spot, using the method of Bottcher et al. (15).

The percentage of phospholipid hydrolyzed after treatment of erythrocyte with phospholipase $A_{2}$ was determined by measuring the ratio of remaining diacylglycerophospholipid to the corresponding lyso derivative. The relative quantity of sphingomyelin (SM) recovered was determined by comparing the results obtained from the oxidant samples with the absolute and relative quantity of SM recovered from the nontreated control sample.

Scanning electron microscopy for morphology. Erythrocyte morphology was determined by the method previously described by Snyder et al. (9). 500 cells were counted at random and the percent of erythrocytes with echinocytic morphology was determined for each hydrogen peroxide concentration used.

Deformability measurements. We measured the deformability of intact erythrocytes and resealed erythrocyte ghosts in an ektacytometer. This device imposes a well-defined laminar shear stress field on the cells, while simultaneously monitoring the extent of cell deformation by laser difractometry. A deformability index (DI) is obtained which is equivalent to the ellipticity of the deforming cells $(16,17)$. In the standard mode of operation, DI is recorded continuously as a function of shear rate. For measurement of intact erythrocyte deformability, $10 \mu \mathrm{l}$ of a $40 \%$ erythrocyte suspension was thoroughly mixed with $3 \mathrm{ml}$ of polyvinyl pyrolidone (molecular weight $360,000,4 \mathrm{~g} / \mathrm{gl} \mathrm{wt} / \mathrm{vol}, 32.6 \mathrm{cp}$ at $20^{\circ} \mathrm{C}$, $290 \mathrm{mosmol} / \mathrm{kg}, \mathrm{pH}$ 7.4). This suspension produced a maximum stress of $170 \mathrm{dyn} / \mathrm{cm}^{2}$ at $100 \mathrm{rpm}$. Numerical values of the DI reached, defined at $\mathrm{DI}_{\max }$, were used to compare the deformability of different samples. For measurement of the deformability of resealed membranes, $30 \mu \mathrm{l}$ of packed, resealed ghosts $\left(\sim 250 \times 10^{6}\right)$ were suspended in $3 \mathrm{ml}$ Stractan ( $22 \mathrm{cp}$ viscosity, $290 \mathrm{mosmol} / \mathrm{kg}, \mathrm{pH}$ 7.4) (18).

Resealed ghosts for membrane deformability measurements were prepared by a procedure adapted from Johnson (19). The erythrocytes were first washed three times in $140 \mathrm{mM} \mathrm{NaCl}, 5 \mathrm{mM}$ Tris- $\mathrm{HCl}$, pH 7.4 (resealing buffer). They were then lysed in $40 \mathrm{vol}$ of ice-cold hypotonic medium consisting of $7 \mathrm{mM} \mathrm{NaCl}, 5 \mathrm{mM}$ Tris- $\mathrm{HCl}, \mathrm{pH} 7.4$ (lysing buffer). After hemolysis was complete, the hemolysate was centrifuged at 15,000 rpm for 10 min in an RC-5 centrifuge (Dupont Co., Sorvall Instruments Div., Newtown, CT), and the supernatant was removed. Ghosts were resuspended in 10 vol of resealing buffer. They were incubated at $37^{\circ} \mathrm{C}$ for $1 \mathrm{~h}$ to promote resealing. Subsequent centrifugation at $15,000 \mathrm{rpm}$ for 5 min produced a concentrated ghost suspension for the membrane deformability measurements.

Assay of erythrocyte-monocyte interaction. Monocytes were isolated from heparinized blood by Ficoll-Hypaque density gradient as previously described (20). The mononuclear leukocytes were washed and suspended to $1 \times 10^{6}$ monocytes/ml in culture medium (RPMI 1640; Gibco Laboratories, Grand Island, NY) supplemented with $10 \%$ heat-inactivated fetal calf serum (Gibco Laboratories), and $100 \mu / \mathrm{ml}$ penicillin-streptomycin. A half milliliter of mononuclear cell suspension was placed on 13-mm glass coverslips in 16-mm diameter wells of tissue culture plates (Linbro, Flow Laboratories, McLean, VA). The wells containing the mononuclear cells were incubated at $37^{\circ} \mathrm{C}$ in air $/ 5 \% \mathrm{CO}_{2}$ for $60 \mathrm{~min}$, and at the end of the incubation period, the nonadherent cells were washed away gently with PBS. The adherent cells were more than $95 \%$ monocytes as defined by nonspecific esterase staining and the viability was higher than $98 \%$ as defined by the trypan blue dye exclusion test. Approximately $4 \times 10^{5}$ monocytes were present on each coverslip as determined by direct counting at an inverted phase microscope. 
Table I. Methemoglobin Lipid Peroxidation (LP) and Spectrin-Hemoglobin Cross-Linking Formation Following $\mathrm{H}_{2} \mathrm{O}_{2}$ Exposure to Normal Human Erythrocytes

\begin{tabular}{|c|c|c|c|c|}
\hline \multicolumn{2}{|l|}{ Additives } & \multirow{2}{*}{$\begin{array}{l}\text { Methemo- } \\
\text { globin }\end{array}$} & \multirow[b]{2}{*}{ LP + Units* } & \multirow{2}{*}{$\begin{array}{l}\mathrm{Sp} / \mathrm{Hb} \\
\text { Crosslinking }\end{array}$} \\
\hline $\mathrm{H}_{2} \mathrm{O}_{2}$ & BHT‡ & & & \\
\hline$\mu M$ & & $\%$ & & $\%$ \\
\hline Control & & $0.15 \pm 0.05$ & $2.5 \pm 0.3$ & 0 \\
\hline 45 & & $2.1 \pm 0.1$ & $2.5 \pm 0.2$ & 0 \\
\hline 135 & & $3.8 \pm 0.3$ & $4.1 \pm 0.8$ & 0.97 \\
\hline 225 & & $5.6 \pm 0.4$ & $6.0 \pm 0.97$ & 2.7 \\
\hline 225 & + & $5.7 \pm 0.5$ & $4.2 \pm 0.4$ & - \\
\hline 315 & & $9.5 \pm 0.6$ & $8.6 \pm 1.2$ & 3.7 \\
\hline 315 & + & $9.6 \pm 0.5$ & $6.4 \pm 0.4$ & - \\
\hline 810 & & $29.5 \pm 1.5$ & $11.4 \pm 0.4$ & 5.4 \\
\hline 810 & + & $30.1 \pm 3.4$ & $8.0 \pm 0.2$ & 5.9 \\
\hline 810 & $+\operatorname{co\S }$ & $0.2 \pm 0.04$ & $12.4 \pm 1.4$ & 0 \\
\hline
\end{tabular}

* Units represent fluorescent changes standardized with quinine sulfate (see Methods).

$\ddagger$ BHT $(0.2 \mathrm{mM})$ incubated for $30 \mathrm{~min}$ before exposure of $\mathrm{H}_{2} \mathrm{O}_{2}$. $\S$ Carbon monoxide gas equilibrated.

"The mean \pm 1 SD from four different experiments (see Methods).

$\mathrm{O}$ Rh-positive controls and $\mathrm{H}_{2} \mathrm{O}_{2}$-treated erythrocytes were sensitized with either a $20 \%$ concentration of anti-D antibody (Rhogam; Ortho Diagnostics, Piscataway, NJ) used as positive controls or with the commercially available rabbit poly specific anti-human globulin (Ortho Diagnostics). To $0.2 \mathrm{ml}$ washed packed erythrocytes were added three drops of anti-D serum, or $0.4 \mathrm{ml}$ rabbit poly specific anti-human globulin, followed by incubation at $37^{\circ} \mathrm{C}$ for $60 \mathrm{~min}$ in a shaking water bath. At the end of the incubation, the sensitized erythrocytes were washed three times in $10 \mathrm{vol}$ of PBS to remove the unattached protein, and then they were suspended at a final concentration of $2 \times 10^{8}$ cells $/ \mathrm{ml} .100 \mu \mathrm{l}$ of this suspension was added to the monolayers of monocytes previously overlaid with $0.4 \mathrm{ml}$ culture medium (target/effector ratio of 50:1). After the erythrocytes and monocytes were incubated in air $/ 5 \% \mathrm{CO}_{2}$ for $2 \mathrm{~h}$ at $37^{\circ} \mathrm{C}$, the nonphagocytized and nonadhering erythrocytes were removed by gentle washing with PBS. The cells were fixed with $1.25 \%$ glutaraldehyde in PBS for $10 \mathrm{~min}$ and stained with Giemsa solution. The coverslips were mounted on glass slides and 500 monocytes were examined on duplicate slides to determine the percentage of monocytes phagocytizing and/or having attached erythrocytes. A ratio of phagocytized and adherent erythrocytes per monocyte was computed as well.

\section{Results}

Methemoglobin formation and lipid peroxidation. After $\mathrm{H}_{2} \mathrm{O}_{2}$ exposure from 45 to $135 \mu \mathrm{M}$, no significant changes were observed in either intracellular cation content or the erythrocyte volume and hemoglobin concentration (data not shown).

Table I illustrates the effect of $\mathrm{H}_{2} \mathrm{O}_{2}$ on methemoglobin formation, lipid peroxidation, and spectrin-hemoglobin cross-linking. The data show that increased methemoglobin content can first be seen at a $\mathrm{H}_{2} \mathrm{O}_{2}$ concentration of $45 \mu \mathrm{M}$ while increased lipid peroxidation and presence of spectrin-hemoglobin complex are first seen at $\mathrm{H}_{2} \mathrm{O}_{2}$ concentration of $135 \mu \mathrm{M}$. Subsequently, a dose-dependent increase in methemoglobin, lipid peroxidation, and spectrin-hemoglobin complex is seen as $\mathrm{H}_{2} \mathrm{O}_{2}$ concentration is increased from 135 to $810 \mu \mathrm{M}$. Spectrin-hemoglobin crosslinking was detected as an additional band integrating at the trailing edge of the alpha chain of spectrin with a molecular weight of 255,000 . A progressive decrease in the staining intensity of the alpha chain of spectrin relative to the beta chain was also noted (Fig. 1), which is consistent with $\mathrm{H}_{2} \mathrm{O}_{2}$ consumption of alpha spectrin chain complex formation as previously reported using isolated components (4).

Maximal effect of $\mathrm{H}_{2} \mathrm{O}_{2}$ was seen after $15 \mathrm{~min}$ of incubation. Extending the incubation period up to $3 \mathrm{~h}$ showed no additional cellular changes. Prior incubations with the antioxidant, BHT,
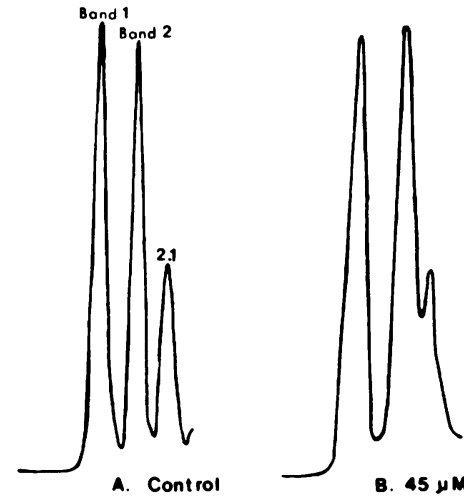

B. $45 \mathrm{MM}$

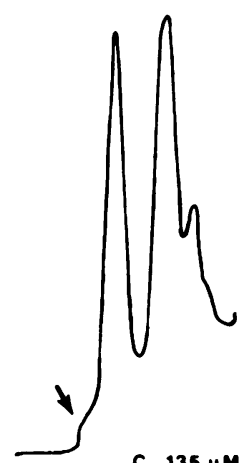

C. $135 \mu \mathrm{M}$
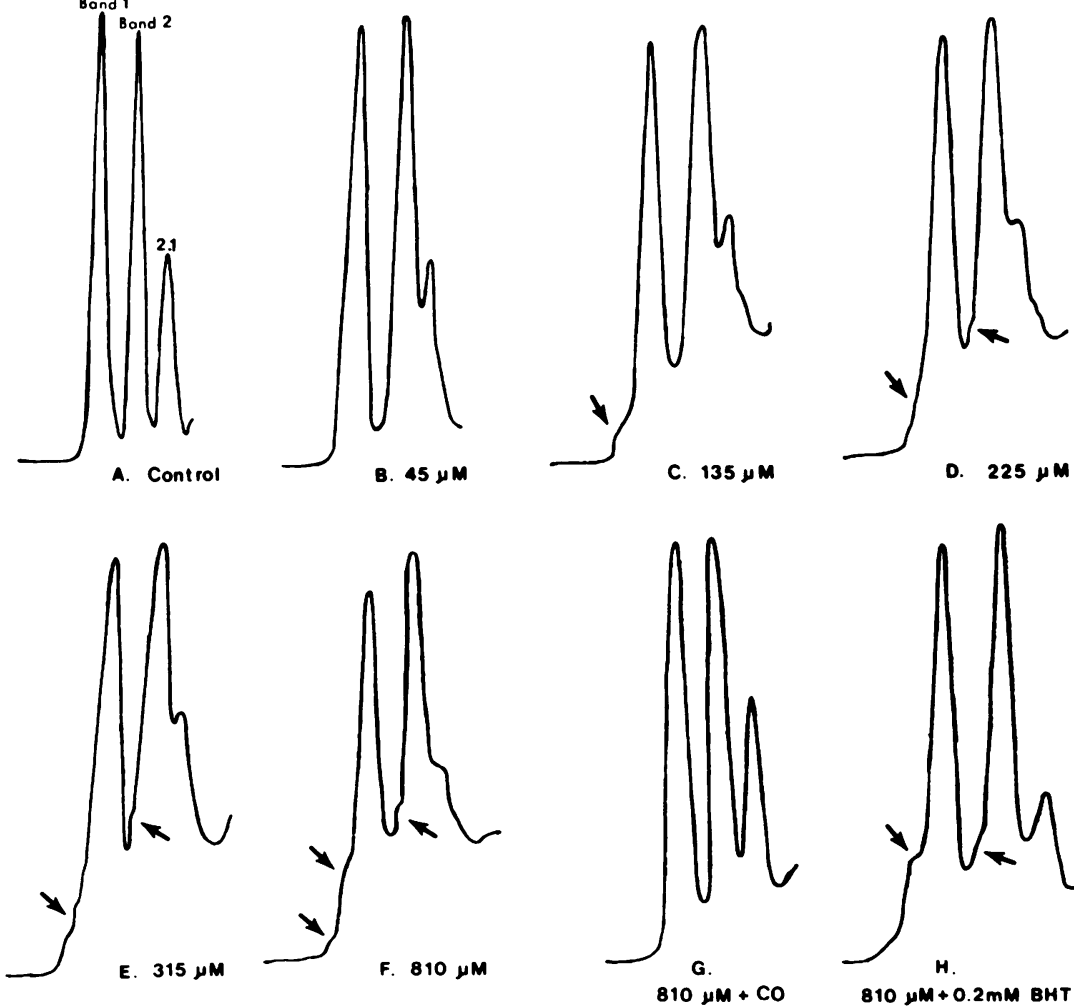

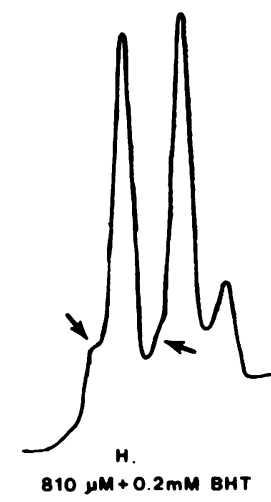

Figure 1. Densitometric scans of the spectrin region, bands 1 and 2, of SDS-4\% PAGE from $\mathrm{H}_{2} \mathrm{O}_{2}$-treated erythrocytes. Arrows point to spectrin-hemoglobin cross-linking. 
Table II. Phospholipid Accessibility in Normal $\mathrm{H}_{2} \mathrm{O}_{2}$-treated Erythrocytes by Phospholipases

\begin{tabular}{|c|c|c|c|c|c|c|c|}
\hline \multicolumn{2}{|c|}{ Additives } & & \multicolumn{4}{|c|}{ Phospholipid degradation } & \multirow{2}{*}{$\begin{array}{l}\text { Decrease in PC } \\
\text { degradation }\end{array}$} \\
\hline$\overline{\mathrm{H}_{2} \mathrm{O}_{2}}$ & BHT & & $\overline{\mathrm{PC}}$ & $\mathrm{PE}^{*}$ & PS & $\overline{S M}$ & \\
\hline$\mu M$ & & & $\%$ & $\%$ & $\%$ & $\%$ & $\%$ \\
\hline \multirow[t]{2}{*}{ Control } & & $A_{2}$ alone & 69 & 11 & 0 & 0 & 0 \\
\hline & & $A_{2}+$ sm'ase & 80 & 22 & 0 & 66 & \\
\hline 135 & & $A_{2}$ alone & 63 & 13 & 0 & 0 & 6 \\
\hline \multirow[t]{2}{*}{225} & & $A_{2}$ alone & 64 & 13 & 0 & 0 & 8 \\
\hline & & $A_{2}+$ sm'ase & 78 & 23 & 0 & 67 & \\
\hline \multirow[t]{2}{*}{315} & & $A_{2}$ alone & 59 & 11 & 0 & 0 & 15 \\
\hline & & $A_{2}+$ sm'ase & 81 & 23 & 0 & 75 & \\
\hline \multirow[t]{2}{*}{810} & & $A_{2}$ alone & 54 & 13 & 0 & 0 & 19 \\
\hline & & $A_{2}+$ sm'ase & 79 & 25 & 0 & 72 & \\
\hline \multirow[t]{2}{*}{810} & $+\mathrm{CO}$ & $A_{2}$ alone & 69 & 15 & 0 & 0 & 0 \\
\hline & $+\mathrm{CO}$ & $A_{2}+$ sm'ase & 79 & 26 & 0 & 64 & \\
\hline
\end{tabular}

* Abbreviations used in this table: PE, phosphatidylethanolanine; PS, phosphatidylserine; sm'ase, sphingomylinase.

at $0.2 \mathrm{mM}$ partially inhibited lipid peroxidation but had no effects on either methemoglobin formation or generation of spectrinhemoglobin complex. In contrast, pretreatment of erythrocytes with carbon monoxide completely inhibited methemoglobin formation and the generation of spectrin-hemoglobin complex while having no effect on lipid peroxidative damage.

Membrane phospholipid organization of $\mathrm{H}_{2} \mathrm{O}_{2}$ to the erythrocytes. Our study of erythrocyte membrane phospholipid organization after $\mathrm{H}_{2} \mathrm{O}_{2}$ exposure, using the combination of bee venom phospholipase $A_{2}$ and sphingomyelinase, did not reveal any major differences in the phospholipid degradation pattern between normal and peroxide-treated cells (Table II). Our results show that the transbilayer distribution of phospholipid remains unchanged after exposure to $\mathrm{H}_{2} \mathrm{O}_{2}$, with the amino-phospholipids being predominantly localized in the inner lipid leaflet.

Although $\mathrm{H}_{2} \mathrm{O}_{2}$ treatment did not induce transbilayer redis- tribution of phospholipids, it did appear to have an effect on lateral organization of membrane phospholipids. As $\mathrm{H}_{2} \mathrm{O}_{2}$ concentration was increased from $135 \mu \mathrm{M}$, a progressive decrease in phosphatidylcholine (PC) degradation was noted after treatment with bee venom phospholipase $A_{2}$ (Table II). BHT had no effect on PC degradation (data not shown). However, carbon monoxide treatment, which prevented methemoglobin and spectrin-hemoglobin cross-linking, also normalized PC degradation.

Functional alterations associated with spectrin-hemoglobin cross-linking. Studies were carried out in order to analyze the association of spectrin-hemoglobin cross-linking with critical membrane functions, such as erythrocyte morphology, erythrocyte deformability, and surface characteristics.

Shape change. Fig. 2, $A-H$ illustrates the morphology of erythrocytes after exposure to varying concentrations of $\mathrm{H}_{2} \mathrm{O}_{2}$. $2.5 \%$ of the cell population were echinocytes following treatment with $135 \mu \mathrm{M} \mathrm{H}_{2} \mathrm{O}_{2}$. A progressively increasing number of echinocytes were noted as the concentration of $\mathrm{H}_{2} \mathrm{O}_{2}$ increased (Fig. $2 G$ ). Pretreatment of erythrocytes with the antioxidant, BHT, had no effect on echinocyte formation (Fig. $2 G$ ), while prior incubation with carbon monoxide completely inhibited the echinocyte formation (Fig. $2 \mathrm{H}$ ).

Erythrocyte membrane deformability. Deformability measurements on intact erythrocytes showed that treatment with hydrogen peroxide resulted in a dose-dependent decrease in whole-cell deformability and that the observed reduction in deformability may be related to increased membrane rigidity. Direct evidence for increased membrane rigidity of treated erythrocytes was obtained by measuring the deformability characteristics of resealed membranes as opposed to whole cells. Fig. $3 \mathrm{~A}$ shows the DI vs. shear rate for resealed membranes prepared from control and variously treated erythrocytes. Membranes from peroxide-treated erythrocytes had reduced deformability compared with control membranes at all values of applied shear
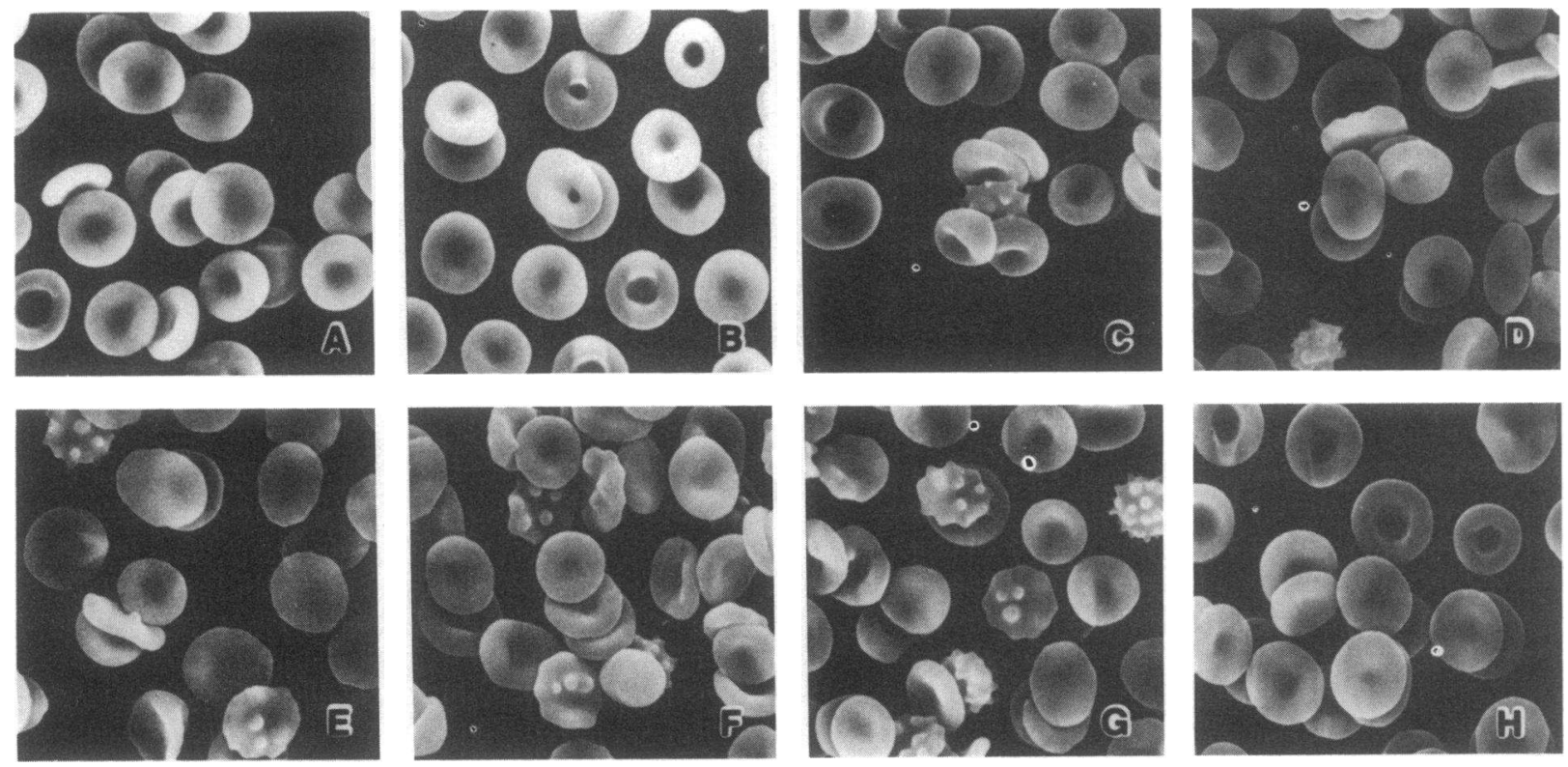

Figure 2. Cell shape. SEM of glutaraldehyde-fixed erythrocytes following exposure to $\mathrm{H}_{2} \mathrm{O}_{2} .500$ cells counted and the percentage of the number of echinocytes determined. $(A)$ control, <1\% echinocytes; $(B)$ $45 \mu \mathrm{M},<1 \%$ echinocytes; (C) $135 \mu \mathrm{M}, 2.5 \%$ echinocytes; (D) $225 \mu \mathrm{M}$,

$5.6 \%$ echinocytes; $(E) 315 \mu \mathrm{M}, 9.4 \%$ echinocytes; $(F) 810 \mu \mathrm{M}, 15.5 \%$ echinocytes; $(G) 810 \mu \mathrm{M}+0.2 \mathrm{mM}$ BHT, $18.9 \%$ echinocytes; $(H) 810$ $\mu \mathrm{M}+\mathrm{CO},<1$ echinocyte. $A-H, \times 1,500$. 

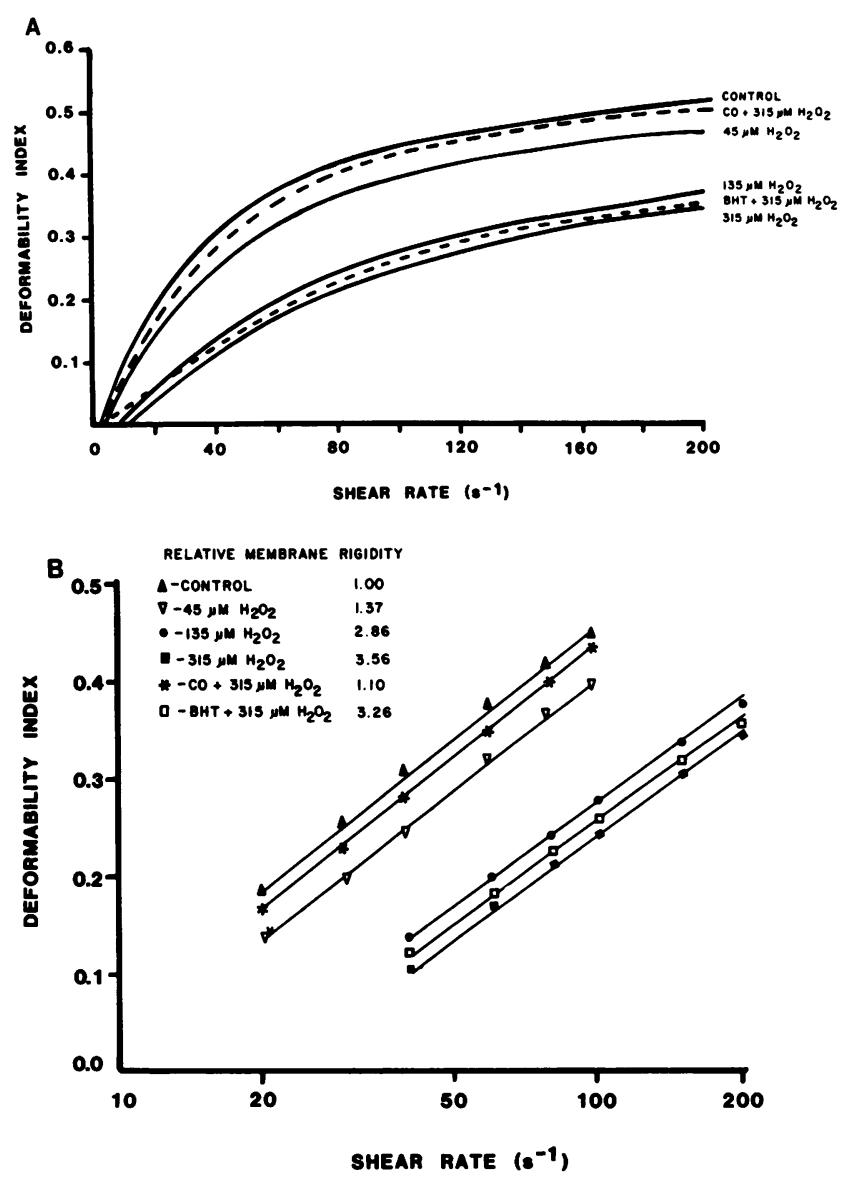

Figure 3. (A) DI vs. shear stress for resealed erythrocyte membranes from $\mathrm{H}_{2} \mathrm{O}_{2}$-treated erythrocytes. $(B)$ Deformability data from resealed membranes from control $+\mathrm{H}_{2} \mathrm{O}_{2}$-treated erythrocytes plotted as DI vs. logarithm of shear rate.

stress (shear stress-shear rate $\times$ suspending medium viscosity). Pretreatment of erythrocytes with carbon monoxide-inhibited peroxide-induced increases in membrane rigidity. In contrast, membranes from erythrocytes pretreated with BHT became as rigid upon treatment with peroxide as control erythrocytes. When the deformability data from resealed membranes were replotted as DI vs. logarithm of shear rate, a linear relationship was seen between the two variables (Fig. $3 \mathrm{~B}$ ). The lines for membranes from peroxide-treated erythrocytes were parallel to those of control membranes, but were displaced to higher values of applied shear rate. This implied that to obtain equivalent membrane deformation, membranes from peroxide-treated erythrocytes required higher values of applied shear stress compared with control membranes. The magnitude of displacement is a direct measure of increased rigidity. As compared with control membranes, the relative rigidity of membranes from erythrocytes treated with 45,135 , and $315 \mu \mathrm{m}$ of peroxide was $1.37,2.86$, and 3.56, respectively. Prior treatment with carbon monoxide totally abolished peroxide-induced increase in rigidity while relative rigidity of BHT-treated erythrocytes was very similar to that of normal cells (3.26 vs. 3.56 ).

The membranes from peroxide-treated erythrocytes also exhibited modest dose-dependent increases in membrane stability. Pretreatment with carbon monoxide completely inhibited the increase in membrane stability while BHT treatment did not alter the response to peroxide treatment (data not shown).
Surface alterations as manifested by monocyte phagocytosis. Table III shows data on adherence and subsequent phagocytosis of normal and $\mathrm{H}_{2} \mathrm{O}_{2}$-treated cells by monocytes. The adherence of the erythrocytes treated with $\mathrm{H}_{2} \mathrm{O}_{2}$ to monocytes was the first sign of surface alteration. Cell adherence showed a maximum effect at $315 \mu \mathrm{M}$, in contrast with phagocytosis, which behaved in a more dose-dependent fashion. The antioxidant, BHT, had no effect on either adherence or phagocytosis, while preincubation of erythrocytes with carbon monoxide completely inhibited both adherence and phagocytosis. Prior incubation of the monocytes with either $0.68 \mathrm{mg}$ of human IgG or $0.68 \mathrm{mg}$ gamma globulin/500,000 monocytes completely inhibited both adherence and phagocytosis of oxidized erythrocytes (data not shown).

\section{Discussion}

The data obtained during the present study show that hydrogen peroxide induces a covalent complex of spectrin and hemoglobin as well as a myriad of cellular changes which include alteration in cell shape, membrane deformability, phospholipid organization, and cell surface characteristics. As erythrocytes were treated with increasing concentrations of hydrogen peroxide, they became progressively more echinocytic, their membrane rigidity increased, and cell surface alterations occurred which could be recognized by monocytes. The formation of spectrinhemoglobin complex, as well as all the cellular changes, could be completely inhibited by prior exposure of erythrocytes to carbon monoxide, indicating that peroxidation of heme proteins plays a crucial role in the observed changes. Lipid peroxidation does not appear to be important since prior treatment of erythrocytes with the antioxidant, BHT, inhibited the generation of fluorescent amino immunopropene derivatives upon exposure to hydrogen peroxide, but was unable to inhibit the formation of spectrin-hemoglobin complex or the various cellular changes.

The generation of echinocytes after exposure to hydrogen

Table III. Phagocytosis of $\mathrm{H}_{2} \mathrm{O}_{2}$-treated Erythrocytes by Fresh, Peripheral Blood Monocytes

\begin{tabular}{|c|c|c|c|}
\hline \multicolumn{2}{|l|}{ Additives } & \multirow[b]{2}{*}{ Adherence* } & \multirow[b]{2}{*}{ Phagocytosist } \\
\hline $\mathrm{H}_{2} \mathrm{O}_{2}$ & BHT§ & & \\
\hline$\mu M$ & & $\%$ & $\%$ \\
\hline \multirow[t]{2}{*}{ Control } & & $4.8 \pm 2.2$ & $4.6 \pm 1.2$ \\
\hline & + & $4.0 \pm 2.4$ & $6.2 \pm 1.8$ \\
\hline 135 & & $20.0 \pm 3.1$ & $7.4 \pm 1.8$ \\
\hline 315 & & $25.0 \pm 2.3$ & $8.6 \pm 1.0$ \\
\hline 315 & + & $20.0 \pm 4.5$ & $7.6 \pm 1.2$ \\
\hline 810 & & $25.0 \pm 3.5$ & $13.2 \pm 2.1$ \\
\hline 810 & + & $25.0 \pm 4.1$ & $13.5 \pm 2.6$ \\
\hline 810 & $++\mathrm{CO}^{\prime \prime}$ & 2.5 & 3.0 \\
\hline
\end{tabular}

* 500 monocytes counted; the number of monocytes with adherent erythrocytes is counted and expressed as a percentage of total monocytes.

$¥ 500$ monocytes counted; the number of monocytes with engulfed erythrocytes is counted and expressed as a percentage of total monocytes.

$\S$ BHT $(0.2 \mathrm{mM})$ incubated for $30 \mathrm{~min}$ before exposure to $\mathrm{H}_{2} \mathrm{O}_{2}$. "Plus carbon monoxide gas equilibrated. The mean \pm 1 SD from four different experiments. 
peroxide appears to be related to peroxidation of membrane protein, including spectrin-hemoglobin complex, since carbon monoxide treatment which inhibited the formation of this complex also inhibited cell shape transformation. The mechanism of echinocyte formation may be related to condensation of the inner monolayer lipids as a result of spectrin-hemoglobin complex formation. The bilayer couple hypothesis entails that a decrease in inner lipid monolayer area will result in echinocyte formation $(21,22)$.

Our deformability data on resealed membranes shows that cross-linking of spectrin-hemoglobin appears to be related to alterations in deformability as shown by increasing membrane rigidity. Comparing deformability alteration after treatment with carbon monoxide and BHT enabled us to show that change in deformability is related to membrane protein peroxidation, as evidenced by the formation of spectrin-hemoglobin complex, and is not related to lipid peroxidation. The significance of the relationship between the deformability changes and spectrinhemoglobin complex formation probably indicates a more generalized functional effect of oxidation on various skeletal proteins and their interactions. The direct role of spectrin-hemoglobin complex on deformability is, therefore, questioned because of the small amount that is present, even in spite of the fact that there appears to be a preference of the globin subunits of hemoglobin for the alpha chain of spectrin. The latter would increase the percentage of the complex formation to a maximum of $12 \%$ on the alpha chain of spectrin, and thus would seem to indicate the importance of location and not the amount of the complex. The relevancy of these in vitro studies to an in vivo situation has recently been reinforced by our unpublished data, which showed that the most dense, normal human erythrocytes isolated on Percoll-Hypaque density gradients contained spectrin-hemoglobin complex (1) and the membranes of these cells were indeed more rigid (Mohandas, N., N. Fortier, and L. M. Snyder, unpublished observation).

Peroxide-treated erythrocytes also undergo changes in their surface characteristics, as was shown by alterations in the accessibility of PC, as well as by increased phagocytosis and adherence to peripheral blood monocytes. These results correlated positively with the formation of spectrin-hemoglobin complex, and were inhibited by the preincubation of erythrocytes with carbon monoxide but uneffected by prior exposure to BHT. These data support the concept that perturbation within the skeletal system, which is tethered to the intrinsic membrane by linkage proteins, may alter the surface of the erythrocyte (23). Similar observations were reported in experiments using spectrin antibodies that induced a transmembrane aggregation of binding sites located on the outer membrane surface (24). Eventually, these structural alterations on the surface were not related to increased accumulation of immunoglobulins but rather to the presence of new antigen sites (24).

In the present study, we have demonstrated that a component in the rabbit polyspecific anti-human globulin is necessary for monocyte recognition of alterations in the surface characteristics of oxidized erythrocytes. This component is very likely an immunoglobulin, which binds to the FC receptor of the monocyte, since both phagocytosis and adherence were essentially blocked by prior incubation of the monocytes with either human IgG or gamma globulin.

Our results, which indicate that the transbilayer distribution of phospholipids remains undisturbed following exposure to hydrogen peroxide, are at variance with those reported by Jain
(25). However, the hydrogen peroxide concentration we used is much lower than that used by Jain. It is likely that the low concentration of hydrogen peroxide in the present experiments did not cause a drastic modification of the erythrocyte skeleton and, therefore, was insufficient to cause a loss of phospholipid asymmetry (26). In contrast, the progressive decrease in phosphatidylcholine degradation after hydrogen peroxide treatment signifies an effect on lateral organization of membrane phospholipids which has also been shown to be dependent upon the integrity of the membrane skeletal structures (27). It is noteworthy that there is evidence that erythrocyte membrane phospholipids do not represent a single pool of phospholipids, but each (i.e., PC) may reside in specific domains (28-30). Each domain may have a different susceptibility to phospholipase degradation. One of the determinants of accessibility of a particular domain to the phospholipase is the packing pressure (31). The change in surface pressure or lipid packing following hydrogen peroxide exposure could be multifactorial. One could be due to change in lipid interaction as a consequence of hydrogen peroxide-induced alteration in lipid structure, such as from unsaturated to saturated. It is also conceivable that a change in membrane protein-lipid interaction can give rise to an alteration in lipid packing. The fact that $\mathrm{CO}$ inhibited spectrin-hemoglobin cross-linking, and did not inhibit lipid peroxidation, together with the fact that the $\mathrm{CO}$ treatment prevented hydrogen peroxideinduced abnormal phospholipase $\mathrm{A}_{2}$ degradation pattern, strongly suggests that the hydrogen peroxide-induced alterations in membrane lipid packing are the result of altered membrane protein-lipid interaction.

In summary, we suggest that the mechanisms by which low levels of hydrogen peroxide, or eventually other oxidants, induce changes in the erythrocyte characteristics are due to a reaction on the inside of the erythrocyte involving oxidation of heme proteins resulting in their cross-linking to skeletal proteins, i.e., spectrin and actin (32), and in addition, to the cytoplasmic component of band 3 (33).

The erythrocyte membrane skeleton consists of an extensive complex self-associating network of proteins composed principally of spectrin, which is complexed with actin, band 4.1, and band 4.9. Spectrin, in turn, is associated with the cytoplasmic surface of band 3, the major spanning integral membrane protein by a linkage protein, ankyrin (band 2.1) (34). Thus, peroxidation, which results in globin cross-linking to any one or all of these interrelated proteins, may lead to a decrease in deformability, as well as morphologic and surface changes in the erythrocyte. The combined alterations both on the inside and outside, mediated by a chemical reaction in the skeletal system of a normal erythrocyte, provides a sequential mechanism to explain oxidative erythrocyte destruction. The critical defect or the chain of events that occurs is still undefined and is the object of our present research.

\section{Acknowledgments}

The authors wish to acknowledge the comments and suggestions made by Dr. Grant Fairbanks of the Worcester Foundation for Experimental Biology.

The work was supported by grants from the National Institutes of Health: R01 H1119933 (Dr. Snyder), PO1 Am32094 (Dr. Lubin), and AM26263 (Dr. Mohandas); funds from the Harold G. and Leila Y. Mathers Charitable Foundation of White Plains, NY; and the St. Vincent Hospital Research Foundation, Worcester, MA. 


\section{References}

1. Snyder, L. M., L. Leb, J. (Piotrowski) Trainor, N. Sauberman, S. C. Liu, and N. L. Fortier. 1983. Irreversible spectrin-haemoglobin crosslinking in vivo: a marker for red cell senescence. Br. J. Haematol. 53:379-384.

2. Nash, G. B., and H. J. Meiselman. 1981. Red cell ageing: changes in deformability and other possible determinants of in vivo survival. Microcirculation. 1:255-284.

3. Kay, M. M. B. 1975. Mechanism of removal of senescent cells by human macrophages in situ. Proc. Natl. Acad. Sci. USA. 72:3521-3525.

4. Sauberman, N., N. L. Fortier, W. Joshi, J. Piotrowski, and L. M. Snyder. 1983. Spectrin-hemoglobin crosslinkages associated with in vitro oxidant hypersensitivity in pathologic and artificially dehydrated red cells. Br. J Haematol. 54:15-28.

5. Leb, L., P. Beatson, N. L. Fortier, and L. M. Snyder. 1983. The phagocytosis of circulating red blood cells $(\mathrm{RBC})$ by fresh human monocytes. Blood. 62:5a. (Abstr.)

6. Snyder, L. M., S. C. Liu, F. Garver, N. Fortier, J. Piotrowski, L. Leb, and G. Fairbanks. 1983. Direct demonstration of HB associated with purified spectrin from senescent human red cells. Blood. 62:40a. (Abstr.)

7. Mohandas, N., J. A. Chasis, and S. Shohet. 1983. The influence of membrane skeleton on red cell deformability, membrane material properties and shape. Semin. Hematol. 20:225-242.

8. Sheetz, M. P. 1983. Membrane skeletal dynamics: role in modulation of red cell deformability, mobility of transmembrane proteins, and shape. Semin. Hematol. 20:175-188.

9. Snyder, L. M., N. Sauberman, H. Condara, J. Dolan, J. R. Jacobs, I. O. Szymanski, and N. L. Fortier. 1981. Red cell membrane response to hydrogen peroxide sensitivity in hereditary xerocytosis and in other abnormal red cells. Br. J. Haematol. 48:435-444.

10. Goldstein, B. D., M. G. Rozen, and M. A. Amoruso. 1979. Relation of fluorescence in lipid-containing red cell membrane extracts to in vivo lipid peroxidation. J. Lab. Clin. Med. 93:687-694.

11. Rose, H. G., and M. Oklander. 1965. Improved procedure for the extraction of lipids from human erythrocytes. J. Lipid Res. 6:428431 .

12. Lubin, B., D. Chiu, J. Bastacky, B. Roelofsen, and L. L. M. van Deenen. 1981. Abnormalities in membrane phospholipid organization in sickle erythrocytes. J. Clin. Invest. 67:1643-1649.

13. Zwaal, R. F. A., B. Roelofsen, P. Comfurius, and L. L. M. van Deenen. 1975. Organization of phospholipids in human red cell membranes as detected by the action of various purified phospholipases. Biochim. Biophys. Acta. 406:83-96.

14. Roelofsen, B., and R. F. A. Zwaal. 1976. The use of phospholipases in the determination of asymmetric phospholipid distribution in membrane. Methods Membr. Biol. 7:147-177.

15. Bottcher, C. J. F., C. M. van Gent, and C. Pries. 1961. A rapid and sensitive sub-micro-phosphorous determination. Anal. Chim. Acta. 24:203-208.

16. Bessis, M., and N. Mohandas. 1975. A diffractometric method for the measurement of cellular deformability. Blood Cells. 1:307-313.

17. Mohandas, N., M. R. Clark, M. S. Jacobs, and S. B. Shohet.
1980. Analysis of factors regulating erythrocyte deformability. J. Clin. Invest. 66:563-573.

18. Heath, B. P., N. Mohandas, J. L. Wyatt, and S. B. Shohet. 1982. Deformability of isolated red blood cell membranes. Biochim. Biophys. Acta. 691:211-219.

19. Johnson, R. M. 1975. The kinetics of resealing of washed erythrocyte ghosts. J. Membr. Biol. 22:231-253.

20. Leb, L., T. Crusberg, N. Fortier, and L. M. Snyder. 1983. Evaluation of methods using adherence to substrate and density gradient for the isolation of human monocytes. J. Immunol. Methods. 58:309-321.

21. Sheetz, M. P., and S. J. Singer. 1974. Biological membranes as bilayer couples. A molecular mechanism of drug-erythrocyte interactions. Proc. Natl. Acad. Sci. USA. 72:4457-4461.

22. Evans, E. A. 1974. Bending resistance and chemically induced moments in membrane bilayers. Biophys. J. 14:923-931.

23. Fowler, V., and V. Bennett. 1978. Association of spectrin with its membrane attachment site restricts lateral mobility of human erythrocyte integral membrane proteins. J. Supramol. Struct. 8:215-221.

24. Nicolson, G. L., and R. G. Painter. 1973. Anionic sites of human erythrocyte membranes. II. Antispectrin-induced transmembrane aggregation of the binding sites for positively charged colloidal particles. J. Cell Biol. 59:395-406.

25. Jain, S. K. 1984. The accumulation of malonyldialdehyde, a product of fatty acid peroxidation, can disturb aminophospholipid organization in the membrane bilayer of human erythrocytes. J. Biol. Chem. 259:3391-3394.

26. Lubin, B., and D. Chiu. 1982. Membrane phospholipid organization in pathologic human erythrocytes. Prog. Clin. Biol. Res. 97:137150.

27. Rimon, G., N. Meyerstein, and Y. I. Henis. 1984. Lateral mobility of phospholipids in the external and internal leaflets of normal and hereditary spherocytic human erythrocytes. Biochim. Biophys. Acta. 775: 283-290.

28. Marinetti, G. V., and K. Cattieu. 1982. Asymmetric metabolism of phosphatidylethanolamine in the human red cell membrane. J. Biol. Chem. 257:245-248.

29. Shukla, S. D., and D. J. Hanahan. 1982. Identification of domains of phosphatidylcholine in human erythrocyte plasma membranes. J. Biol. Chem. 257:2908-2911.

30. Schrier, S. L., D. T. Chiu, M. Yee, K. Sizer, and B. Lubin. 1983. Alteration of membrane phospholipid bilayer organization in human erythrocytes during drug-induced endocytosis. J. Clin. Invest. 72:16981705.

31. Demel, R. A., W. S. M. G. VanKessel, R. F. A. Zwaal, B. Roelofsen, and L. M. Van Deenen. 1975. Relation between various phospholipase actions on human red cell membranes and the interfacial phospholipid pressure in monolayers. Biochim. Biophys. Acta. 406:97107.

32. Shaklai, N., B. Frayman, N. Fortier, and L. M. Snyder. 1984. Cytoskeletal proteins crosslinking with hemoglobin: a model for red cell peroxidative damage. Blood. 64:31 a. (Abstr.)

33. Waugh, S. M., and P. S. Low. 1985. Hemichrome binding to band 3: nucleation of Heinz bodies on the erythrocyte membrane. Biochemistry. 24:34-39.

34. Schrier, S. L. 1985. Red cell membrane biology: introduction. Clin. Haematol. 14:1-12. 